\title{
Antiphospholipid syndrome: a clinical and laboratorial challenge
}

\author{
luci Maria Santana Dusse ${ }^{1}$, Fernanda Dias e Silva ${ }^{1}$, Letícia Gonçalves Freitas ${ }^{1}$, Danyelle Romana Alves Rios², Sandra \\ Cristina Armond², Milena Soriano Marcolino ${ }^{3 *}$ \\ ${ }^{1}$ Department of Clinical and Toxicological Analyses of the Federal University of Minas Gerais *UFMG) Faculty of Pharmacy, Belo Horizonte, MG, Brazil. \\ ${ }^{2}$ Federal University of São João Del-Rei/Mid-West Campus, São João Del Rei, MG, Brazil. \\ ${ }^{3}$ Medical Clinic Department of the Federal University of Minas Gerais *UFMG) Faculty of Pharmacy Medical School, Belo Horizonte, MG, Brazi.
}

Study conducted at the Federal University of Minas Gerais Medical School, Belo Horizonte, MG, Brazil.

Articled received: 04/10/2013 Accepted for publication: 08/30/2013

*Correspondence:

Address: Av. Professor Alfredo Balena, 110 , sala 246 Belo Horizonte, MG - Brazil Zip Code: 30130-100 Phone: +55 31 3409-9746 milenamarc@gmail.com http://dx.doi.org/10.1590/1806-9282.60.02.016 Conflict of interest: none

\section{SUMMARY}

Antiphospholipid syndrome (APS) is an acquired autoimmune thrombophilia characterized by the presence of a heterogeneous family of antibodies that bind to plasma proteins with affinity for phospholipid surfaces. The two major protein targets of antiphospholipid antibodies are prothrombin and $\beta_{2}$-glycoprotein I ( $\beta 2$ GPI). APS leads to aprothrombotic state, and it is characterized by the occurrence of arterial, venous or microvascular thrombosis or recurrent fetal loss. The diagnosis of APS is based on a set of clinical criteria and the detection of lupus anticoagulant (LA), anticardiolipin antibodies (ACA) or anti- $\beta_{2}$ GPI in plasma. Although laboratory tests are essential for APS diagnosis, these tests have limitations associated with the robustness, reproducibility and standardization. The standardization of diagnostic tests for detection of APLAs has been a challenge and a variety of results have been obtained using different commercial kits and in-house techniques. An increased sensitivity of the ELISA kits for detection of ACA effectively has contributed to APS diagnosis. However, the lack of specificity associated with a high number of false-positive results is a clinical and laboratorial challenge, since such results may lead to mistaken clinical decisions, such as prescription of oral anticoagulant, leading to the risk of hemorrhaging. Furthermore, clinicians are often unfamiliar with these tests and have difficulty interpreting them, requiring interaction between clinical and laboratory professionals in order to ensure their correct interpretation.

Key words: antiphospholipid syndrome, clinical diagnosis, laboratorial tests, pre-analytical phase.

\section{INTRODUCTION}

Antiphospholipid syndrome (APS) is an acquired autoimmune thrombophilia characterized by the presence of a heterogeneous family of antibodies that bind to plasma proteins with affinity for phospholipid surfaces. The two major protein targets of antiphospholipid antibodies are prothrombin and $\beta_{2}$-glycoprotein I $\left(\beta_{2} G P I\right)$, but these antibodies are also formed against other proteins. ${ }^{1,2}$

APS may occur as a primary condition or related to an underlying disease, generally systemic lupus erythematosus. ${ }^{3}$ APS leads to aprothrombotic state, and it is characterized by the occurrence of arterial, venous or microvascular thrombosis or gestational complications (re- current fetal loss or late complications related to the placenta). ${ }^{1,3}$ It is a rare condition: less than $1 \%$ of patients diagnosed with thrombosis present circulating antiphospholipid antibodies (APLAs). However, it is associated with high morbidity owing to recurrent thrombotic complications. $^{3}$

Its pathophysiology differs from other conditions causing a predisposition to hypercoagulability, whose thrombotic complications develop at specific sites in the vascular network. ${ }^{4}$ In APS, on the other hand, there is no predilection for any territory, and thrombi can affect both arteries and veins, regardless of their caliber, including 
small microcirculation capillaries. This observation allows us to infer that the thrombotic process in APS is independent from the classical regulation of hemostasis, in which endothelial cells play a prominent role.,

Genetic and environmental factors determine the occurrence and clinical expression of APS. Genetic predisposition has been described in studies that have identified an association with HLA-DR4,-DR7, DRw53 and-DQB1*0302 haplotypes. Infections such as hepatitis C virus, human immunodeficiency virus, human herpes virus, adenovirus, parvovirus B19, leprosy and syphilis, or exposure to drugs such as procainamide, phenothiazine, quinine, oral contraceptives and anti-tumor necrosis factor can determine the production APLA. ${ }^{5}$

APS may progress with manifestations of recurrent arterial and/or venous thrombosis, gestational complications (fetal death after 10 weeks of pregnancy, premature birth due to severe preeclampsia or placental insufficiency or recurrent miscarriages) and thrombocytopenia, as well as livedo reticularis or other skin disorders, autoimmune hemolytic anemia, valvular heart disease, nephropathy, pulmonary, ocular, hepatic, splenic, pancreatic, and intestinal and neurological changes. ${ }^{6-8}$ In rare cases, thrombosis can occur in multiple vascular territories, resulting in multiple organ failure, a condition called catastrophic antiphospholipid syndrome. ${ }^{9}$

The presence of APLAs does not always result in thrombosis or gestational complications and the antibodies may be identified in healthy individuals. ${ }^{3}$ The diagnosis of APS is based on a set of clinical and laboratorial criteria and is often difficult to establish. This article aims to review the diagnostic evaluation of APS, highlighting the limitations of the diagnostic criteria and the difficulties in their interpretation.

\section{Diagnostic evaluation}

In suspected clinical cases of APS, a thorough medical history and complete medical examination should be undertaken, as well as the laboratory tests required for diagnosis.

The diagnosis of APS is based on a set of clinical, laboratorial and experimental criteria established in Sapporo, Japan, in the year of 1999, reviewed at the V Meeting of the European Forum on Antiphospholipid Antibodies in Barcelona, Spain, in 2005, and subsequently at a workshop at the International Congress on Antiphospholipid Antibodies in Sydney, Australia, in 2006. ${ }^{10}$
The diagnosis of APS requires at least one clinical and one laboratorial criterion to be present.

\section{Clinical criteria}

1. Vascular thrombosis.

a. One or more episodes of arterial or venous thrombosis in any tissue or organ confirmed by diagnostic imaging or histopathology. Superficial thrombophlebitis does not satisfy this criterion;

2. Gestational morbidity;

a. One or more unexplained deaths of morphologically normal fetuses after the $10^{\text {th }}$ week of pregnancy, with fetal morphology documented by ultrasound imaging or direct examination of the fetus; or

b. One or premature births of morphologically normal newborns (documented by ultrasound) with 34 weeks of pregnancy or less, resulting from preeclampsia, eclampsia or serious placental insufficiency; or

c. Three or more spontaneous, consecutive, unexplained abortions prior to the $10^{\text {th }}$ week of pregnancy, with the exclusion of hormonal or maternal anatomical abnormalities, as well as paternal or material chromosomal abnormalities.

\section{Laboratorial criteria}

1. Presence of lupus anticoagulant (LA) in plasma on two or more occasions in a 12 week interval, detected in accordance with the criteria established by the International Society on Thrombosis and Hemostasis (ISTH)..$^{10}$

2. Presence of anticardiolipin antibodies (ACA), IgG or IgM in the plasma, in amounts of over $40 \mathrm{GPL}$ (IgG antiphosphoLipid) or MPL (IgM antiPhosphoLipid) or above the $99^{\text {th }}$ percentile in two or more separate occasions with a 12 week interval, determined by enzyme-linked immunosorbent assay (ELISA).

3. Presence of anti- $\beta_{2}$ glicoproteín 1 (anti- $\beta_{2}$ GP1), IgG or IgM in the plasma above the $99^{\text {th }}$ percentile on two or more occasions with a 12 week interval, determined by enzyme-linked immunosorbent assay (ELISA).

The Sapporo criteria have some limitations. Some patients with high clinical suspicion of APS cannot meet the modified criteria. The clinical findings that do not meet the criteria of the APLAs but are associated with them include valvulopathy, livedo reticularis, thrombocytopenia, nephropathy and neurological manifestations. 


\section{LABORATORY EXAMS IN APS}

The laboratorial diagnosis of APS is undertaken through the detection of LA, ACA or anti- $\beta_{2}$ GPI in the plasma, denominated in conjunction as APLA. ${ }^{11}$ The risk of thromboembolic phenomena and the level of certainty of the diagnosis increases with the level of APLAs and the number of different positive tests for the same patient. In a case-control study on 208 patients under investigation for APS, each $10 \mathrm{U}$ increase in ACA, igM or IgC was associated with a $5-7 \%$ increase in the risk of thromboembolism, and each additional test with a positive result was associated with a $50-70 \%$ increase in the chance of thromboembolic events. ${ }^{12}$

In general, there is no recommendation for screening asymptomatic individuals to identify those at high risk of thrombotic or gestational complications. The proportion of false positives in asymptomatic individuals in different studies varies from 3 to $20 \%$. False-positive results can lead to patient concern and unnecessary recommendation of anticoagulation, exposing the patient to the risk of hemorrhagic complications. ${ }^{13}$

Furthermore, routine screening for APS is not recommended in patients with thromboembolism who have other risk factors for thromboembolic events. ${ }^{14}$

\section{Precautions in the pre-analytical phase}

Obtaining the test sample under optimal conditions for the detection of APLAs is a major challenge for the clinical laboratory. It is important that the patient is not using anticoagulants, but if so, it is preferable to use the ACA and anti- $\beta_{2}$ GPI tests, which are not affected by the use of these drugs. The LA can show false-positive or false-negative results. In patients taking warfarin, some authors suggest that it is possible to perform the exam when the INR is less than 3.5 and the patient's plasma is diluted (1:2) with normal plasma, while other authors argue that the LA assay should not be perfomed in patients without warfarin withdrawal. ${ }^{15}$

It is an essential condition to ensure the removal of platelets from the sample because they present phospholipids on their surface, which neutralize part of the APLAs present, compromising the test result. The filtration of the sample in a $0.22 \mu$ filter is recommended as a secure way of removing platelets. However, this procedure is associated with two negative aspects. The first is the cost of the filter and the second the reduction of the levels of von Willebrand factor in the sample. Ultracentrifugation has also been proposed as a way to ensure the removal of plasma platlets. However, besides the need of the ultracentrifuge in the clinical laboratory, this procedure must be performed carefully to avoid the fragmentation of platelets and maintenance of the fragments in the sample. ${ }^{16}$ In other words, it is merely of historical significance and should not be applied in laboratory practice.

According to NCCLS Guidelines H3-A5 and H21-A4, the sample for tracing APLAs must be collected in sodium citrate $(0.109 \mathrm{M})$ at a ratio of 9:1 in plastic or siliconized tubes. The sample should be centrifuged for 15 minutes at 2 to $2.5 \mathrm{~g}$, and the supernatant should be transferred to another tube and centrifuged again for 15 minutes at 2 to $2.5 \mathrm{~g}$. The platelet count should be less than $10 \mathrm{x}$ $10^{9} / \mathrm{L}$, i.e. less than $10 / \mathrm{mm}^{3}{ }^{3}{ }^{16}$

\section{Anticardiolipin}

Cardiolipin is a negatively charged phospholipid, weakly expressed on the cell membrane, which is preferably located in the inner mitochondrial membrane. As it can be easily obtained from bovine heart, cardiolipin was standardized as a phospholipid in the solid phase tests. ${ }^{17}$

Among the three antibodies, immunoassay for ACA is the most sensitive, but is not very specific. ${ }^{18}$ Infectious processes can determine the transient ACA positivity. $\mathrm{Pa}-$ tients with syphilis, Lyme disease, HIV and other infections such as the Epstein-Barr virus, cytomegalovirus and hepatitis $\mathrm{C}$ may be mistakenly diagnosed with APS based on high ACA levels when a concomitant cerebrovascular accident or arterial thrombosis is present. ${ }^{13}$ In general, these patients have high levels of AL and anti- $\beta_{2}$ GPI.

For the detection of anticardiolipin antibodies (IgM and $\operatorname{IgG}$ ) the ELISA method is used, which measures the immune reactivity to phospholipids or $\beta_{2}$ GPI, a protein bound to phospholipids. The ELISA test uses microplates coated with highly purified cardiolipin, usually in the presence of bovine serum $\beta 2$-glycoprotein, which acts as a cofactor for the recognition of the antigen (cardiolipin). ACA antibodies from patients with APS are dependent on the $\beta_{2}$ GPI, while the antibodies of those with infectious diseases are independents. ${ }^{19}$

The results relating to IgG are expressed in GPL units and for IgM in MPL units, with a GPL or MPL unit corresponding to the binding activity of $1 \mathrm{mg} / \mathrm{mL}$ of $\mathrm{IgG}$ or IgM, respectively. ${ }^{20}$ According to the ISTH, the results are considered positive when greater than 40 LPG or MPL or the $99^{\text {th }}$ percentile on two or more occasions separated by a 12 week interval.

Despite the fact that ELISA for detection of IgM and IgG ACA antibodies were standardized since the first symposium on APLAs in 1987, an analysis of the literature reveals that it is not always clear in the publications if this standardization has been rigidly followed. This makes it 
impossible to compare results, which has made it necessary to develop recommendations to standardize laboratory methods and the expression of the results. ${ }^{11}$ Although laboratory results are of fundamental importance for the diagnosis of APS, many questions still remain unanswered regarding the methodology employed and the reference values of the various kits commercially available that are not concordant. Thus, it is recommended that each laboratory should use the $99^{\text {th }}$ percentile from their own controls in order to determine the cutoff value for average titers. ${ }^{21,22}$

Favaloro et al. ${ }^{23}$ evaluated the correspondence of inter-laboratory ACA (IgG and IgM) dosage results and found a coefficient of variation (CV) of more than $50 \%$ in $71 \%$ of the samples evaluated, indicating the high variability of this measurement. A careful evaluation of laboratory results is essential, with repetition of these tests at least once before the diagnostic conclusion.

It is important to repeat the test 12 weeks after an initial positive result. The persistence of ACA in the serum is a necessary criterion for establishing the APS diagnosis. ${ }^{11,24}$

\section{Anti- $\beta_{2}$-glycoprotein I antibodies}

The tests that measure anti- $\beta_{2}$ GPI are more specific (98\%), although they are less sensitive (40 to 50\%) for APS than the ACA. ${ }^{13}$

\section{Lupus anticoagulant}

There are several tests for LA. The Antiphospholipid Antibodies Subcommittee of the International Society of Thrombosis and Hemostasis has proposed specific criteria to standardize the evaluation for LA. ${ }^{9}$ For reasons as yet unknown, the tests are frequently negative for one method but positive for another. Thus, it is recommended to perform two tests based on different test principles whenever there is suspicion of APS. ${ }^{9}$ The two preferred tests are dilute Russell's viper venom time (dRVVT) and activated partial thromboplastin time (aPTT) ${ }^{13}$ The dRVVT should be the first choice and is widely used in clinical laboratories, as it is believed to be specific for the detection of LA in patients with a high risk of thrombi.

The APLAs interfere with the aPTT, given that this test uses an optimized amount of phospholipid (cephalin) to trigger the coagulation cascade in vitro after the addition of calcium. Thus, in samples containing APLAs, these antibodies may neutralize some of cephalin and compromise the sequential activation of factors that culminate in the breakdown of fibrinogen to fibrin. Since the activation of the coagulation cascade is delayed, the coagulation formation time is consequently extended. A great deal of attention is therefore required for the correct interpretation of this test. This result suggests a deficiency of coagulation factors and presupposes that the patient is presenting bleeding. However, in practice, there is a tendency toward thromboembolic events in patients with APLAs. Currently, there are various kits available on the market for determining aPTT containing cephalins with different sensitivities for triggering the coagulation cascade. However, checking the instructions for using these kits did not reveal specific information or guidance regarding the evaluation of LA.

The repetition of the aPTT using one part of the patient's plasma and one part normal plasma (mixture test) is essential for the correct diagnosis. ${ }^{11,22}$

Although the prothrombin time (PT) also uses phospholipid to trigger the coagulation cascade in vitro (calcium thromboplastin), this test includes an excess of thromboplastin which even if a part of which is neutralized by the APLAs, there would still remain sufficient thromboplastin to start the reaction, so that prolongation is not observed.

The search for LA should be performed in 3 sequential stages: screening, mixtures with normal plasma and confirmation. ${ }^{11}$ The screening stage consists of using two tests that are based on different principles. The dRVVT is the initial examination because the reagent contains Russell's viper venom, phospholipids, calcium, prothrombin, factor $\mathrm{V}$, and a heparin inhibitor. The second test is the aPTT. Kits that use silica or ellagic acid as activators should be avoided due to their low sensitivity to $\mathrm{AL},{ }^{25}$ as well as kits that use kaolin as an activator, as they are unstable and do not present reproducibility in automated coagulometers.

Screening tests should be performed using plasma from healthy donors and the cutoff point defined as above the $99^{\text {th }}$ percentile. The presence of LA is confirmed when one or both tests are positive, that is, if the results are greater than the established cutt-off value..$^{25}$

The second stage, mixing with normal plasma, is intended to show that prolongation of aPTT is caused by a specific inhibitor, given that in other conditions, such as deficiencies in coagulation factors XII, XI, X, IX, VIII, $\mathrm{V}, \mathrm{II}$ and I, prolongation of this test also occurs. ${ }^{11}$

These coagulation factor deficiencies may be excluded using a mixture of test plasma with normal plasma at a 1:1 ratio without pre-incubation for 30 minutes. The addition of the normal plasma provides factors to the deficient plasma at sufficient levels to normalize the test. In contrast, the correction of the aPTT after the addition of normal plasma does not occur in APS. ${ }^{11,24}$ 
In the presence of coagulation factor inhibitors of, such as anti-factor VIII antibodies, which often occurs in hemophilia A, the aPTT is prolonged due to the reduction in the levels of this factor. After the 1:1 mixture with normal plasma the test is immediately corrected. However, the test becomes prolonged again after 1 or 2 hours at $37^{\circ} \mathrm{C}$, as during this period the F VIII inhibitor binds to the F VIII in the normal plasma, thereby inhibiting it.

In samples from patients with APS, the addition of phospholipids to the test plasma results in a reduction of the clotting time, confirming the presence of LA. ${ }^{11,24}$

The presence of LA cannot be definitively confirmed if the thrombin time in the plasma tested is significantly prolonged. The cut off is defined as greater than the $99^{\text {th }}$ percentile. Alternatively, the cut off may be the value of the circulating antibody index (CAI) defined according to the equation: $\mathrm{CAI}=[(\mathrm{b}-\mathrm{c}) / \mathrm{a}] \times 100$, in which $\mathrm{a}, \mathrm{b}$ and $c$ are the coagulation times of sick patient's plasma, the mixture and the normal plasma, respectively. ${ }^{25}$

The third step is the confirmatory stage, characterized by the dependent nature of the phospholipid inhibitor. It uses a reagent with a high concentration of phospholipids (higher than that used in screening) to demonstrate that the prolongation of the coagulation time is consistent with the presence of LA in the sample. ${ }^{1124}$ It is known that Russell's viper venom directly activates factor $\mathrm{X}$ and triggers the coagulation cascade, which is followed by the activation of prothrombin into thrombin and the consequent breakdown of fibrinogen into fibrin. This test is therefore independent of the deficiencies of the contact phase factors (XII, prekallikrein and high-molecular-weight kininogen) and those related to hemophilia (factors VIII, IX and XI), as well as the presence of inhibitors of these factors. ${ }^{26}$

The tests must be performed on plasma from healthy donors into low (screening) and high (confirmatory) phospholipid concentrations. The cut off corresponds to the average of individual corrections (\%) calculated using the equation [(screening, confirmatory)/screening] $\times 100$. The results are confirmatory for the LA if the correction percentage is above the established cut-off value. ${ }^{25}$

\section{Conclusion}

APS is a multisystem disorder associated with a variety of circulating antibodies whose targets are distinct phospholipid complexes. The main clinical manifestations of APS are fetal loss and arterial and/or venous thromboembolic complications.

The diagnosis of APS is based on a set of clinical and laboratorial criteria. Despite the updates to these criteria, the diagnosis remains difficult to establish. Detection of LA, ACA or anti- $\beta_{2}$ GPI in plasma present limitations associated with the robustness, reproducibility and standardization of methods.

Tests for the detection of APLAs must be sufficiently sensitive to correctly classify patients as APS positive, and highly specific, given that false-positive results can lead to mistaken clinical decisions, such as the prescription of oral anticoagulants, thereby leading to the risk of bleeding.

The standardization of diagnostic tests for APLAs has been a challenge, as a variety of results have been obtained using different commercial kits and in-house techniques. An increase in sensitivity of ELISA kits for the detection of ACA has contributed effectively to the diagnosis of APS. Furthermore, clinicians are often unfamiliar with these tests and have difficulty interpreting them, requiring interaction between clinical and laboratory professionals in order to ensure their correct interpretation.

\section{ACKNOWLEDGEMENTS}

CNPq and FAPEMIG.

\section{Resumo}

Síndrome do anticorpo antifosfolípide: um desafio clínico e laboratorial

A síndrome do anticorpo antifosfolípide (SAAF) é uma trombofilia autoimune adquirida, caracterizada pela presença de uma família heterogênea de anticorpos que se ligam a proteínas plasmáticas com afinidade, por superfícies fosfolipídicas. As duas principais proteínas-alvo dos anticorpos antifosfolípides (AAF) são a protrombina e a $\beta_{2}$-glicoproteína 1 ( $\beta_{2}$ GP1). A SAAF está associada a um estado protrombótico e é clinicamente caracterizada pela ocorrência de trombose arterial, venosa ou microvascular ou perda fetal recorrente. O diagnóstico da SAAF é baseado em um conjunto de critérios clínicos e na detecção plasmática de anticoagulante lúpico (AL), anticorpo anticardiolipina (ACA) ou anti$\beta_{2}$ GP1. Embora os testes laboratoriais sejam de fundamental importância para o diagnóstico da SAAF, eles apresentam limitações associadas à robustez, à reprodutibilidade e à padronização. A padronização de testes diagnósticos para a pesquisa de AAF tem sido um desafio, pois uma variedade de resultados pode ser obtida utilizando diferentes kits comerciais e técnicas in-house. Um aumento da sensibilidade dos kits de ELISA para a detecção do ACA contribuiu efetivamente para o diagnóstico da SAAF. No entanto, a falta de especificidade, associada a um número elevado de resultados falso-po- 
sitivos, é um desafio clínico e laboratorial, uma vez que tais resultados podem levar a decisões clínicas erradas, como a prescrição de anticoagulante oral, levando ao risco de hemorragia. Além disso, os clínicos muitas vezes não estão familiarizados com esses testes e têm dificuldade em interpretá-los, sendo necessária a interação da clínica e dos profissionais do laboratório para assegurar sua correta interpretação.

Unitermos: síndrome do anticorpo antifosfolípide; síndrome antifosfolipídica; diagnóstico clínico; testes laboratoriais; fase pré-analítica.

\section{RefEREnces}

1. Hughes GRHN, Gharavi AE. The anticardiolipin syndrome. J Rheumatol 1986; 13(3):486-9.

2. Backer Jr. WF, Bick RL. The clinical spectrum of antiphospholipid syndrome. Hematol Oncol Clin North Am 2008; 22(1):33-52.

3. De Groot PG. Mechanisms of anti-phospholipid antibody formation and action. Thromb Res 2011; 127(Suppl 3):S40-S2.

4. Aird WC. Spatial and temporal dynamics of the endothelium. J Thromb Haemost 2005; 3(7):1392-406.

5. Peluso SAA, De Rosa A, Roca A, Maddaluno G, Brescia Morra V, De Michele G. Antiphospholipid-related chorea. Front Neurol 2012; 3:1-7.

6. Hadi HA, Treadwell EL. Lupus anticoagulant and anticardiolipin antibodies in pregnancy: a review. Immunochemistry and clinical implications. Obstet Ginecol Surv 1990; 45(11):780-5.

7. Borchers AT, Naguwa SM, Keen CL, Gershwin ME. The implications of autoimmunity and pregnancy. J Autoimmun 2010; 34(3):J287-J99.

8. Greaves M. Antiphospholipid syndrome: unusual clinical presentations. Thromb Res 2011; 127(Suppl 3):S47-S50.

9. Borba EF, Bonfá E, Asherson. RA. Catastrophic antiphospholipid syndrome (Asherson's Syndrome) revealed. J Bras Reumatol 2005; 5(2):374-81.

10. Miyakis S, Lockshin MD, Atsumi T, Branch DW, Brey RL, Cervera R et al International consensus statement on an update of the classification criteria for definite antiphospholipid syndrome (APS). J Thromb Haemost 2006; $4(2): 295-306$
11. Devreese K, Hoylaerts MF. Challenges in the diagnosis of the antiphospholipid syndrome. Clin Chem 2010; 56(6):930-40.

12. Neville CRJ, Kassis J, Chang ER, Joseph L, Le Comte M, Fortin PR. Thromboembolic risk in patients with high titre anticardiolipin and multiple antiphospholipid antibodies. Thromb Haemost 2003; 90(1):108-15.

13. Rand JH WL. Dos and don'ts in diagnosing antiphospholipid syndrome. Hematology Am Soc Hematol Educ Program 2012; 455-9.

14. Pengo VBA, Gresele P, Marongiu F, Erba N, Veschi F, Ghirarduzzi A et al Survey of lupus anticoagulant diagnosis by central evaluation of positive plasma samples. J Thromb Haemost 2007; 5(5):925-30.

15. Miyakis SLM, Atsumi T, Branch DW, Brey RL, Cervera R, Derksen RH et al. International consensus statement on an update of the classification criteria for definite antiphospholipid syndrome (APS). J Thromb Haemost 2006; 4(2):295-306.

16. Sletnes KE, Gravem K, Wisloff F. Preparation of plasma for the detection of lupus anticoagulants and antiphospholipid antibodies. Thromb Res 1992; 66(1):43-53.

17. Gharavi AE, Harris EN, Asherson RA, Hughes GRV. Anticardiolipin antibodies - isotype distribution and phospholipid specificity. Ann Rheumat Dis 1987; 46(1):1-6.

18. Suh-Lailam BB, Cromar A, Davis KW, Tebo AE. APhL antibody ELISA as an alternative to anticardiolipin test for the diagnosis of antiphospholipid syndrome. International J Clin Exp Pathol 2012; 5(3):210-5.

19. Levine JS BD, Rauch J. The antiphospholipid syndrome. N Engl J Med 2002; 346(10):752-63

20. Cecatti JG AM, Tintori EM, Yela DA, Queiroz MLS. Anticorpos anticardiolipina entre gestantes com óbito fetal. RBGO 2000; 22(2):101-6.

21. Pengo V. APS - controversies in diagnosis and management, critical overview of current guidelines. Thromb Res 2011; 127(Suppl 3):S51-S2

22. Pengo V. A contribution to the debate on the laboratory criteria that define the antiphospholipid syndrome. J Thromb Haemost 2008; 6(6):1048-9.

23. Favaloro EJ, Silvestrini R. Assessing the usefulness of anticardiolipin antibody assays - A cautious approach is suggested by high variation and limited consensus in multilaboratory testing. Am J Clin Pathol 2002; 118(4):548-57.

24. Asherson RA, Khamashta MA, Ordiros J, Derksen RH, Machin SJ Barquinero J et al. The primary antiphospholipid syndrome - major clinical and serological features. Medicine 1989; 68(6):366-74.

25. Pengo V, Tripodi A, Reber G, Rand JH, Ortel TL, Galli M et al. Update of the guidelines for lupus anticoagulant detection. Subcommittee on Lupus Anticoagulant/Antiphospholipid Antibody of the Scientific and Standardisation Committee of the International Society on Thrombosis and Haemostasis. J Thromb Haemost 2009; 7(10):1737-40.

26. Thiagarajan P, Pengo V, Shapiro SS. The use of the dilute Russel viper venom for the diagnosis of lupus anticoagulants. Blood 1986; 68(4):869--74 